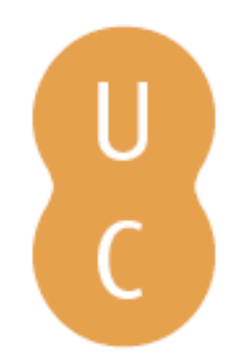

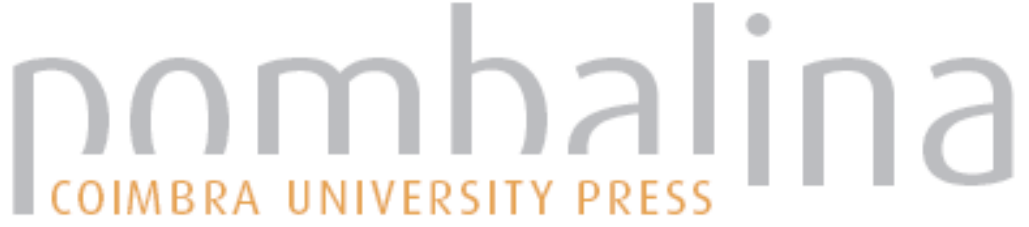

\section{Critérios jurídicos da parentalidade}
Autor(es):
Oliveira, Guilherme de
Publicado por: Imprensa da Universidade de Coimbra
URL persistente:
URI:http://hdl.handle.net/10316.2/38887
DOI:
DOl:http://dx.doi.org/10.14195/978-989-26-1113-6_9

Accessed : $\quad$ 26-Apr-2023 07:07:02

A navegação consulta e descarregamento dos títulos inseridos nas Bibliotecas Digitais UC Digitalis, UC Pombalina e UC Impactum, pressupõem a aceitação plena e sem reservas dos Termos e Condições de Uso destas Bibliotecas Digitais, disponíveis em https://digitalis.uc.pt/pt-pt/termos.

Conforme exposto nos referidos Termos e Condições de Uso, o descarregamento de títulos de acesso restrito requer uma licença válida de autorização devendo o utilizador aceder ao(s) documento(s) a partir de um endereço de IP da instituição detentora da supramencionada licença.

Ao utilizador é apenas permitido o descarregamento para uso pessoal, pelo que o emprego do(s) título(s) descarregado(s) para outro fim, designadamente comercial, carece de autorização do respetivo autor ou editor da obra.

Na medida em que todas as obras da UC Digitalis se encontram protegidas pelo Código do Direito de Autor e Direitos Conexos e demais legislação aplicável, toda a cópia, parcial ou total, deste documento, nos casos em que é legalmente admitida, deverá conter ou fazer-se acompanhar por este aviso.

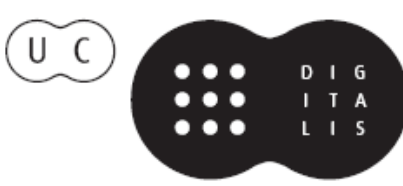




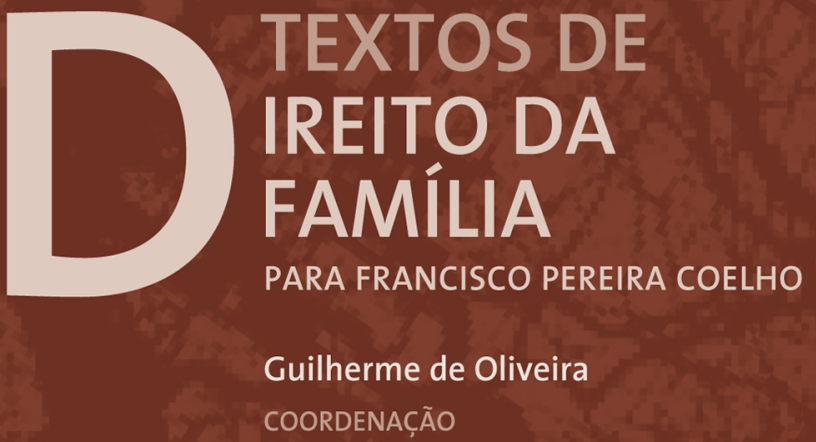




\section{CRITÉRIOS JURÍDICOS DA PARENTALIDADE}

\section{Guilherme de Oliveira}

Professor Aposentado da Faculdade de Direito da Universidade de Coimbra

\section{Sumário}

1. Introdução; 2. Hesitações do "biologismo"; 3. O amor pedocêntrico; 4. A vontade (e o cuidado) como critério da parentalidade; 5. Coresponsabilidades; 6 . Conclusões

\section{Introdução}

No início da minha vida profissional, quando F. Pereira Coelho me sugeriu que estudasse o "estabelecimento da filiação", selecionei dentro dessa área a identificação dos critérios que as leis usavam para atribuir a paternidade. Foi muito formativo pesquisar vários sistemas jurídicos, em várias épocas e diferentes lugares, para verificar que a condição de pai não resultava sempre da aplicação dos mesmos critérios. Em épocas passadas, a preferência dos sistemas jurídicos ia claramente para considerar determinantes certos critérios sociais: a preferência pelo valor do casamento e da instituição matrimonial que impunha a paternidade do marido da mãe, e o respeito pela vontade do homem que podia querer perfilhar ou não perfilhar um filho ilegítimo. Este era o common core de vários sistemas nacionais. 
Nos anos 70, sobretudo nos países latinos, era fácil encontrar algum descontentamento relativamente aos padrões dominantes, por várias razões. Por um lado, os critérios prevalecentes exprimiam os valores sociais da velha ordem social - discriminatória e violenta - que distinguia os filhos legítimos dos ilegítimos e que contemporizava com a vontade arbitrária dos homens que se furtavam facilmente às suas responsabilidades de progenitores. Por outro lado, aqueles valores dominantes já resistiam mal à depreciação crescente da instituições e da heteronomia, designadamente do valor do casamento. Por último, alguns casos mostravam a atribuição da paternidade ao marido da mãe em situações em que a responsabilidade dele era inverosímil ${ }^{1}$, ou a extrema dificuldade para reconhecer juridicamente certos vínculos de progenitura que eram óbvios na realidade ${ }^{2}$.

A reforma de 1977 significou uma alteração enorme no quadro jurídico português. A determinação jurídica da paternidade continuou a respeitar a máxima antiga pater is est quem justae nupciae demonstrant, mas a impugnação da paternidade do marido passou a seguir o regime geral da "prova do contrário", baseada em qualquer facto e sujeita às mesmas práticas de convicção judicial. A negação da paternidade resultava serenamente da demonstração de que o marido era alheio à concepção. Por outro lado, os filhos nascidos fora do casamento tinham liberdade para investigar a paternidade, ora provando diretamente o facto biológico da progenitura, ora beneficiando de presunções que traduziam a probabilidade de o réu ser o progenitor. Em ambos os casos, o esforço probatório exigido

\footnotetext{
${ }^{1}$ Por exemplo, quando a mulher admitia o adultério e exibia intencionalmente a gravidez e o nascimento, eliminando assim a viabilidade da impugnação pelo marido - cfr. o meu Critério jurídico da paternidade, Coimbra, BGUC, 1983, p. 70.

2 "É confrangedor ver a demonstração da filiação biológica ou real, mas a demanda improceder", dizia o juiz Santos SILVEIRA, à semelhança de Mário Stella RICHTER, em Itália - cfr. idem, p. 138.
} 
deixou de exprimir quaisquer preconceitos antigos para passar a ser racional e proporcionado. O sistema, que antes atribuía o estatuto de pai por razões diversas da humilde verificação da progenitura subjacente, deixou de poder ser acusado de favorecer a instituição matrimonial ou a arbitrariedade dos homens. Deixou de interessar se o vínculo nascera de relações sexuais lícitas ou ilícitas, ou se o progenitor queria ou não queria assumir o estatuto jurídico correspondente. O vínculo jurídico da paternidade passou a assentar no vínculo prévio da progenitura e, desde então, a paternidade jurídica coincide com a paternidade biológica - cada um tem o pai que a biologia the deu.

Quanto à maternidade - onde o critério biológico foi sempre mais fácil de seguir pelo caráter ostensivo do vínculo - a acentuação da verdade biológica notou-se principalmente na eliminação da perfilhação pela mãe: a maternidade passou a resultar do facto do nascimento, e a ser estabelecida por uma simples indicação da identidade da mãe.

O regime português justificou assim a qualificação de "biologista".

Tirando o caso nítido da adoção - que nascia da vontade de assumir o papel de pai ou mãe e que se justificava pela perspectiva de construir um vínculo semelhante àquele que assentava na progenitura, no interesse do adotando - as relações de afeto ou de cuidado entre um adulto e uma criança, desacompanhadas de um vínculo biológico prévio, não tinham qualquer influência para sustentar uma relação jurídica parental, nem tinham o mérito de impedir a impugnação de um vínculo jurídico que se supunha assente na progenitura mas que, comprovadamente, não coincidia com a verdade biológica ${ }^{3}$.

\footnotetext{
${ }^{3}$ Isto não é exatamente assim no direito espanhol, ou no francês, quer nas versões antigas quer nas versões atuais. Em França, a verificação da posse de estado restringe a legitimidade para impugnar ao filho, a qualquer dos pais e ao terceiro que se reclama progenitor (art. $333 .{ }^{\circ}$ CCiv francês); e o direito de impugnar caduca
} 
A sujeição do sistema à chamada "verdade biológica" - a "verdade verdadeira" nas palavras de CARBONNIER ${ }^{4}$ - era difícil de contestar: os factos biológicos impunham-se por si, para além das ideologias e dos respetivos preconceitos. Para mais, os meios científicos de prova estavam a desenvolver-se como nunca, por força da prática das transplantações e dos conhecimentos associados de histocompatibilidade, e finalmente pelos progressos da genética.

\section{Hesitações do "biologismo"}

Mas o "biologismo" - que nunca foi um critério absoluto - mostra hoje fragilidades insuspeitadas.

a) Nunca foi um critério absoluto porque se começou a admitir a procriação assistida através da inseminação da mulher com esperma de dador. Este método, que se impôs no direito francês dos anos setenta, generalizou-se na Europa apesar das naturais hesitações que suscitou e foi sem perturbação que entrou no direito português, em 2006. Segundo o art. 20 . $^{\circ}$ da Lei n. ${ }^{\circ} 32 / 2006$, de 26 de julho, o filho que nasce é "...havido como filho do marido ou daquele vivendo em união de facto com a mulher inseminada...", enquanto, nos termos do art. 21. ${ }^{\circ}$, "o dador de sémen não pode ser havido como pai da criança que vier a nascer, não lhe cabendo quaisquer poderes ou deveres em relação a ela". Ou seja, foi sempre admitido por toda a parte que, neste caso, o "pai biológico" não é o pai jurídico. Deste modo, os sistemas jurídicos afastam o critério

depois de cinco anos de posse de estado de filho (idem). Em Espanha, a verificação da posse de estado reduz a legitimidade para impugnar ao filho, ao progenitor registado e a quem for prejudicado na sua qualidade de herdeiro legitimário; e o direito caduca passados quatro anos de posse de estado (art. 140. ${ }^{\circ}$, CCiv espanhol).

${ }^{4}$ Droit Civil, 11 ème éd., t. 2, Paris, PUF, 1979, p. 317. 
biológico para seguirem um critério baseado na vontade de aceitar a prática da inseminação e a de assumir o estatuto de pai.

b) Também se notavam dificuldades na aplicação do critério "biologista" no âmbito da maternidade de substituição. De facto, a gestação por conta de outrem tanto pode ser prestada por uma mulher que insemina o seu próprio óvulo como pode ser suportada por uma mulher que recebe um embrião resultante da fecundação de óvulo alheio - designadamente que pertença à mulher que encomenda a gestação. Em ambos os casos, o critério da maternidade foi sempre o da gestação e do parto, ignorando aquela diferença biológica essencial: no primeiro caso a mãe sub-rogada é mãe genética e mãe gestadora, enquanto no segundo caso a mãe sub-rogada é apenas gestadora. Ou seja, considerando apenas o fundamento biológico da maternidade, ou não se saberia escolher entre a contribuição do património genético e a gestação, ou poderia escolher-se a prevalência da contribuição do património genético, que é mais determinante para o filho, ainda que o valor da gestação seja cada vez mais conhecido e apreciado. Foram certamente razões estranhas ao "biologismo" puro que fizeram prevalecer o critério do parto5.

c) Hoje, o "biologismo" começa a denotar uma nova fragilidade no âmbito do que começa a chamar-se o método ROPA (Reception of oocytes from partner), segundo o qual uma mulher gera embriões

\footnotetext{
5 Em tempos escrevi: “(...) o parto deixa de fornecer um critério biológico exclusivo (e, portanto, indiscutível) para a determinação da maternidade. Assim, a preferência pelo parto como critério jurídico só poderá basear-se no seu valor sócio-afectivo e em razões de ordem prática, como a simplicidade da identificação da mãe nos casos mais frequentes (...). (...) será cada vez mais difícil manter o parto como critério incontestável da maternidade. As mães genéticas hão de procurar impor o reconhecimento da sua ligação biológica; e será relativamente mais fácil diminuir o peso das pretensões da mãe geradora (...). (...) as mães genéticas não aceitarão recorrer a um processo de adopção clássico para constituir um vínculo de filiação com o seu próprio descendente biológico" - Mãe há só tuma duas!, Coimbra, Coimbra Editora, 1992, p. 75-6.
} 
resultantes da inseminação de óvulos da sua companheira, casada ou em união de facto.

O método não tem novidade do ponto de vista técnico porque, afinal, é apenas uma fertilização in vitro de óvulos de uma dadora, com sémen anónimo fornecido por um banco; porém, a dadora tem uma relação de matrimónio ou de união de facto com a recetora. Deste modo, segundo as regras gerais, a mulher que prossegue a gestação e tem o parto será a mãe; a segunda mulher pretende ser a segunda mãe, e invoca a qualidade de prestadora do material genético materno.

O caso mais conhecido é porventura o de uma criança que foi registada em Barcelona com mãe A e mãe B. Pedida a transcrição do registo em Itália, o tribunal de Turim rejeitou a pretensão alegando contrariedade à ordem pública; porém, a $2 .^{a}$ instância admitiu o pedido, com base na defesa da identidade pessoal do filho. Depois de uma suspensão da execução da ordem por parte das autoridades que tutelam o registo civil, para efeitos de esclarecimentos institucionais, o registo foi feito em janeiro de $2015^{6}$.

Este caso italiano significou a procedência dos dois vínculos biológicos concorrentes - o vínculo genético e o vínculo gestacional, ambos dando origem a vínculos jurídicos de maternidade. As autoridades italianas ignoraram a regra de que a mãe é a mulher que tem o parto (art. 269. ${ }^{\circ}$ CCiv italiano) para admitir a equivalência do critério da gestação e do critério da origem genética.

Aparentemente, ocorreu um caso semelhante no Brasil (S. Paulo), em 2011, que também foi resolvido com a da aceitação da dupla maternidade?

\footnotetext{
${ }^{6}$ Cfr. http://it.aleteia.org/2015/01/07/nato-da-una-coppia-lesbica-il-comune-di-torino-ferma-la-trascrizione/

7 Segundo informação do acórdão do Tribunal de Justiça de S. Paulo, acessível em http://ibdfam.org.br/imagens_up/Regi.pdf
} 


\section{O amor pedocêntrico}

Por outro lado, na segunda metade do século vinte, assistiu-se a uma desvalorização clara da instituição matrimonial e a uma ascensão nítida do valor da autonomia - tudo concorrendo para a diminuição do valor do próprio compromisso dos nubentes. O chamado "bem da família", que devia orientar a direção conjunta a par dos interesses de um e do outro cônjuge ${ }^{8}$, tornou-se mais débil no confronto entre os projetos de vida individuais; os deveres recíprocos dos cônjuges ${ }^{9}$ perderam intensidade e até perderam a garantia jurídica do seu cumprimento, desaparecido o divórcio-sem-culpa; a saída do compromisso matrimonial simplificou-se. Numa palavra, a ideia de casamento como "relação pura"10, baseada no compromisso privado que contém em si a possibilidade antecipada da sua dissolução, mostra a grande fragilidade do amor entre os adultos.

Neste quadro de profunda instabilidade, também parece notar-se - como defesa e reação - a hipervalorização da relação com os filhos, que contém a promessa de estabilidade que desapareceu em redor do indivíduo. "O filho, a sua educação e cuidado, podem criar novas referências de sentido e de valores, e pode até converter-se no centro do sentido da existência privada"11. Mesmo que a taxa de natalidade continue baixa, tanto se nota a vontade de não ter filhos como a ansiedade por tê-los. O amor, outrora fiável e entre adultos, tornou-se preferencialmente pedocêntrico.

Se havia um certo pudor em chamar os sentimentos para os terrenos do Direito, e não era costume usar a palavra amor, ou afeição,

\footnotetext{
${ }^{8}$ Art. $1671 .^{\circ}$, n. $^{\circ}$ 2, CCiv.

9 Art. $1672 .^{\circ}$, CCiv.

10 A. GIDDENS - Modernidad e identidad del yo, Barcelona, Península, 1997, p. 237-8.

11 U. BECK y E. BECK-GERNSHEIM - El normal caos del amor, Barcelona, El Roure, 1998, p. 190.
} 
nos escritos jurídicos ${ }^{12}$, a linguagem contemporânea - sobretudo das decisões judiciais - é mais propensa à consideração dos afetos ${ }^{13}$. Para além de alguma perturbação que pode causar na definição do que é o "interesse do filho" por causa da sua vocação totalitária que pode fazer obnubilar os outros fatores relevantes, este caráter pedocêntrico do amor teve consequências no critério emergente que se insinua para definir a parentalidade.

\section{A vontade (e o cuidado ${ }^{14}$ ) como critério da parentalidade}

Notam-se várias manifestações que exprimem a substituição do critério biológico da determinação da parentalidade pelo critério do amor sob a forma da vontade de cuidar e da assunção voluntária da responsabilidade pelo cuidado.

a) A procriação assistida, sob a forma da inseminação com esperma de dador, trouxe a forma mais conhecida de substituição do pai biológico pelo marido da mãe, desde os inícios dos anos 70 . Esta regra impôs-se com um caráter indiscutível, em quase todos os países ${ }^{15}$. Para além de se inscrever o nome do marido no registo

\footnotetext{
12 O código civil português usou a palavra afeição uma vez, na norma que define os critérios para a escolha do tutor pelo tribunal (art. $1931 .^{\circ}, \mathrm{n} .^{\circ} 1$ ).

13 Cfr., por exemplo, os acórdãos da Rel. de Évora de 03.03.2010, da Rel. de Coimbra de 10.16.2012 e de 11.06.2012, da Rel. do Porto de 11.11.2014, da Rel. de Lisboa de 04.29.2014, e da Rel. de Guimarães de 06.12.2014, todos em www.dgsi. pt. Cfr. tb. Rita XAVIER - O público e o privado no direito da família, in "Revista Portuguesa de Filosofia", vol. 70, n. ${ }^{\circ} 4$, 2014, p. 668-672.

${ }^{14}$ Habituei-me a esta palavra com Tânia da Silva PEREIRA, a quem acompanhei como coordenador secundário em O cuidado como valor jurídico, Rio de Janeiro, Forense, 2008; O cuidado e Vulnerabilidade, S. Paulo, Atlas, 2009; Cuidado e Responsabilidade, S. Paulo, Atlas, 2011; Cuidado e Sustentabilidade, S. Paulo, Atlas, 2014.

15 Seguindo o modelo francês. Não assim no sistema alemão e na Escandinávia. O Reino Unido passou a seguir este caminho [The Human Fertilization and Embryology Authority (Disclosure of Donor Information) Regulations 2004].
} 
civil, o filho não podia pretender o reconhecimento da paternidade assente no vínculo biológico, nem sequer descobrir a identificação do dador. E a preocupação de robustecer o papel do marido levou as boas práticas a admitir alguma seleção do dador para que ele tivesse uma aparência semelhante à dele e assim favorecer a aparência da paternidade biológica do marido ${ }^{16}$.

Aparentemente, a vontade de assumir a paternidade na sequência da inseminação com dador, manifestada nos termos da lei, é suficiente; isto é, não se exige a demonstração de atos reiterados de cuidado, embora a manifestação da vontade deixe prever um comportamento típico de pai e a partilha das responsabilidades parentais com a mãe.

$\mathrm{O}$ direito português seguiu estas regras. $\mathrm{Na}$ verdade, segundo o art. $20{ }^{\circ}$ da Lei n. ${ }^{\circ}$ 32/2006, de 26 de julho, "Se da inseminação (...) vier a resultar o nascimento de um filho, é este havido como filho do marido ou daquele vivendo em união de facto com a mulher inseminada (...)"; e, de acordo com o art. 21. ', "O dador de sémen não pode ser havido como pai da criança que vier a nascer, não lhe cabendo quaisquer poderes ou deveres em relação a ela".

b) No direito brasileiro, nasceu no fim dos anos 70 uma corrente forte que favorece a chamada paternidade sócio-afetiva ${ }^{17}$.

João Batista VILlELA escreveu que "ser pai ou ser mãe não está tanto no fato de gerar quanto na capacidade de amar e servir"18. De certo modo, esta ideia não é inovadora, no sentido em que já se praticava, em toda a parte, a atribuição da paternidade sem vínculo

16 Guilherme de OLIVEIRA - Procriação com dador; tópicos para uma intervenção, in "Procriação assistida, Colóquio interdisciplinar, 12-13 de Dezembro de 1991", Coimbra, Centro de Direito Biomédico, 1993, p. 37.

17 Villela, J. B. - Desbiologização da Paternidade. Revista da Faculdade de Direito. Universidade Federal de Minas Gerais, v. 21, p. 401-419, 1979.

18 Idem, n. ${ }^{\circ} 3$. 
biológico. Na verdade, o instituto da adoção é conhecido em todos os sistemas jurídicos com uma configuração semelhante ${ }^{19}$ e o adotante não é, por definição, o progenitor. Por outro lado, o conceito de posse de estado, e os seus três elementos (nomen, tractatus e fama), é um clássico do direito da família, com relevo específico no âmbito da impugnação dos reconhecimentos voluntários, em alguns países ${ }^{20}$. Por último, e mais recentemente, a regra de que o marido, ou o companheiro da mãe, que consente na inseminação com gâmetas de dador é o pai jurídico também foi consagrada em muitos países.

Mas a ideia ampliou-se na doutrina, na jurisprudência e na lei brasileiras. Diz-se que "toda a paternidade é necessariamente socioafetiva, podendo ter origem biológica ou não"21. Em primeiro lugar, sublinhou-se o art. 227.022 da Constituição de 1988, onde se lê que a convivência familiar é a "prioridade absoluta da criança"23. Depois, o código civil de 2002 afirmou "o parentesco é natural ou civil, conforme resulte de consanguinidade ou de outra origem" (art. $1593 .^{\circ} \mathrm{CCiv}$ br). Entendeu-se a noção de parentesco civil como outra maneira de exprimir a verdade sócio-afetiva, que sustenta os vínculos de parentalidade em três tipos de situações: na adoção; no caso de paternidade do marido ou companheiro da mãe inseminada com esperma de dador (art. 1597. ${ }^{\circ}, \mathrm{V}$, br); no caso de posse de

19 Omitindo agora a diferença entre adoção secreta e adoção aberta.

20 Cfr. supra, nota 4.

21 Paulo LÔBO - Socioafetividade: o estado da arte no direito da família brasileiro, "Revista Jurídica Luso-Brasileira", Centro de Investigação de Direito Privado, FDUL, ano 1, 2015, n. ${ }^{\circ}$ 1, p. 1743-1759, p. 1751.

22 "É dever da família, da sociedade e do Estado assegurar à criança, ao adolescente e ao jovem, com absoluta prioridade, o direito à vida, à saúde, à alimentação, à educação, ao lazer, à profissionalização, à cultura, à dignidade, ao respeito, à liberdade e à convivência familiar e comunitária, além de colocá-los a salvo de toda forma de negligência, discriminação, exploração, violência, crueldade e opressão. (...)" (Redação dada Pela Emenda Constitucional n ${ }^{\circ}$ 65, de 2010).

23 Paulo LÔBO - Direito civil - Famílias, 4 . $^{\text {a }}$ ed., São Paulo, Ed. Saraiva, 2011, p. 265; ID. Socioafetividade..., cit., p. 1752-3. 
estado de filho (1601. ${ }^{\circ}$, II, br) ${ }^{24}$. Por outro lado, tem ganho força a ideia de que o conhecimento da paternidade biológica ou da origem genética, possibilitado pelos meios de prova científica, satisfaz um direito fundamental do âmbito do desenvolvimento da personalidade, mas não traduz a verdadeira paternidade, que pertence ao domínio do direito da família, e que é fundamentalmente um facto cultural, afetivo, fundador do "estado de filiação"; "a certeza absoluta da origem genética não é suficiente para fundamentar a filiação, uma vez que outros são os valores que passaram a dominar esse campo das relações humanas" 25 .

Com base nestes desenvolvimentos, o direito brasileiro levou a relevância da posse de estado e da paternidade sócio-afetiva até um ponto mais avançado do que se conhecia ${ }^{26}$.

A posse de estado de filho - mostrando a verdade sócio-afetiva ou a sócio-afetividade - tem um papel relevante quer para (aa)) estabelecer a filiação, quer para (bb)) obstar à sua impugnação.

aa) A doutrina fala de uma "reconfiguração da presunção pater is est..."27, de tal modo que esta também faz presumir a paternidade do

24 Idem, p. 207.

25 Paulo LÔBO, ob.cit., p. 227-8. É esta separação entre o direito ao desenvolvimento da personalidade e o direito da família que explica que a Lei $n .^{\circ}$ 12.010/2009, ao dar nova redação ao Estatuto da Criança e do Adolescente, admita que o adotado possa conhecer a sua origem genética, sem prejuízo da adoção - Paulo LÔBO, Socioafetividade..., cit., p. 1758.

26 Deve notar-se que, neste contexto, os tradicionais elementos da posse de estado não terão exatamente o mesmo sentido que têm quando a posse de estado serve de presunção do vínculo biológico. O tratamento (tractatus) é a manutenção de relações de cuidado como para um filho (elemento objetivo), mas deve incluir o sentimento de responsabilidade pelo cuidado da criança como faria um pai - que não é desempenho de mera atividade profissional, nem caridade transitória (elemento subjetivo); e a reputação pelo público (fama) deve mostrar o aval da comunidade ao compromisso paternal que o homem assumiu - cfr. o meu Critério jurídico da paternidade, Coimbra, BGUC, 1983, p.445-6.

27 A regra mantém o efeito tradicional de presumir a paternidade do marido, quando a paternidade "não tiver sido constituída por outro modo e for inexistente no registro do nascimento, em virtude da incidência do princípio da paternidade 
marido da mãe "que age e se apresenta como pai, independentemente de ter sido ou não o genitor biológico"28; “(...) pai é o marido ou o companheiro que aceita a paternidade do filho, (...) sem questionar a origem genética, consolidando-se o estado de filiação"29.

Nos casos em que não existe ou não é conhecido um registo de nascimento, a parentalidade pode ser estabelecida com base na demonstração da posse de estado de filho ${ }^{30}$. A situação mais comum é a de os pais terem desaparecido ou morrido sem terem promovido o competente registo de nascimento ${ }^{31}$. Trata-se, portanto, de suprir a falta de um registo que podia ter sido feito e que representaria a parentalidade jurídica, fossem ou não os desaparecidos ou falecidos os reais progenitores.

No caso de nascimento fora do casamento ${ }^{32}$, o filho pode propor uma ação de investigação de paternidade. Porém, nesta ação, "o que se investiga é o estado de filiação, que pode ou não decorrer da origem genética" 33 ; daí que a procedência de um exame científico não tem o resultado de o réu ser considerado como pai; apenas lhe dá a qualidade de genitor ${ }^{34}$. Para que a paternidade seja declarada, é

responsável imputada a quem não a assumiu" - Paulo LÔBO, Socioafetividade..., cit, p. 1752; o marido só pode impugná-la por vício da vontade.

28 Paulo LÔBO, ob. cit., p. 247-8.

29 Idem, p. 221.

$30 \mathrm{Em}$ alternativa à apresentação de "começo de prova por escrito" art. 1605. ${ }^{\circ}$ CCiv br - Paulo LÔBO, ob. cit., p. 236-237.

31 Paulo LÔBO, ob. cit., p. 236.

32 A paternidade pode estabelecer-se por perfilhação; mas o filho pode impugná-la, (tenha havido ou não convivência familiar) dentro dos quatro anos posteriores à maioridade (art. $1614 .^{\circ}$, CCiv br). É que o filho é livre de aceitar essa paternidade, ou de a recusar.

33 Idem, p. 265. A investigação da paternidade como origem genética decorre de um direito de personalidade de qualquer indivíduo, e não se confunde com o direito da família.

34 “1. Se o autor foi registrado pelo marido da sua mãe quando já contava 13 anos e sempre soube que não era filho do pai registral, então essa condição de filho restou consolidada como relação jurídica de paternidade socioafetiva que perdurou até o óbito do pai registral, quando já contava 49 anos de idade (...) 4. 
preciso que todo "o conjunto probatório" mostre o "estado de filiação derivado dos laços de afeto construído na convivência familiar"35. No mesmo sentido, "a ação [de investigação da parentalidade] não tem somente a finalidade de atribuir a paternidade ou a maternidade ao genitor biológico. Este é apenas um elemento a ser levado em conta, mas deixou de ser determinante. O que se investiga é o estado de filiação que pode ou não decorrer da origem genética"36. E ainda "Não há como aceitar uma relação de filiação apenas biológica, sem ser afetiva, esta externada quando o filho é acolhido pelos pais, que assumem plenamente suas funções do poder familiar"37.

A utilização da posse de estado também é vulgar no contexto da chamada "adoção à brasileira". Neste caso, uma criança é registada em nome de pessoas que se fazem passar pelos progenitores, e que pretendem criá-la. Na sua base está uma falsificação do estado civil, que é crime de "parto suposto" (art. 242. ${ }^{\circ}$ CPen br). No entanto, a prática da "convivência familiar", e o decurso do tempo, constituem uma posse de estado de filho que passa a merecer a tutela do Direito, por força da norma constitucional que garante à criança o direito à "convivência familiar" (art. 227. ). Entre a rejeição do comportamento criminoso (que afinal a sociedade aprova) e a proteção constitucional, os tribunais usam a prerrogativa do "perdão judicial" para deixar de aplicar a pena em razão de "reconhecida nobreza"38.

\footnotetext{
Não é possível desconsiderar a figura de quem foi sempre o verdadeiro pai do autor, que lhe deu o nome e o sustento, isto é, o amparo material... e moral, bem como o suporte afetivo, ao longo de toda a sua vida, e cujo nome já carrega há mais de cinqüenta anos (...) 5. Se o propósito da parte era conhecer o seu vínculo biológico, tal pretensão foi atendida com o exame de DNA realizado". TJ-RS - Apelação Cível AC 70061424107 RS (TJ-RS), 04/11/2014.

35 Idem, p. 266.

36 Caio Mário da Silva PEREIRA - Instituições de direito civil, vol. V, 22. ${ }^{a}$ ed., rev. e atual. por Tânia da Silva Pereira, Rio de Janeiro, Forense, 2014, p. 412.

37 Rolf MAdaleno, apud Caio Mário da Silva PEREIRA, ob cit, p. 415.

38 Paulo LÔBO, ob. cit., p. 251-2.
} 
É conhecida ainda a aplicação destes conceitos aos "filhos de criação", "que abandonam suas famílias originárias, por variadas contingências da vida, e são inteiramente acolhidos em outra, onde são construídos laços estáveis de afetividade recíproca"39, sem que a família de acolhimento altere o registo civil.

bb) A posse de estado obsta à impugnação da paternidade pelo marido quando, apesar da inexistência de um vínculo biológico entre o filho e o presumido pai, se estabeleceu "o estado de filiação, de natureza socioafetiva" ${ }^{\prime 0}$. Para impugnar a paternidade registada por força da presunção pater is est... o marido tem de "provar não ser o genitor, no sentido biológico (por exemplo, o resultado do exame de DNA) e, por esta razão, não ter sido constituído o estado de filiação, de natureza socioafetiva; e se foi o próprio declarante perante o registro de nascimento, comprovar que teria agido induzido em erro ou em razão de dolo ou coação".

É duvidoso se o conhecimento superveniente de que o pai não foi o genitor lhe permite impugnar o estado de filho que foi constituído antes. O STJ acabou de admitir que, neste caso, houve vício de consentimento da parte do pai, que justifica a impugnação ${ }^{41}$. Mas Paulo LÔBO discorda e afirma em contrário que, "se forem mais fortes a paternidade afetiva e o melhor interesse do filho, enquanto menor, nenhuma pessoa ou mesmo o Estado poderão impugná-la (...)" "42; e ainda "O que determina a filiação ou não são esses fatos

39 Idem, p. 287.

40 Idem, p. 246.

41 O STJ afirmou, em 06.04.2015: "Sem proceder a qualquer consideração de ordem moral, não se pode obrigar o pai registral, induzido a erro substancial, a manter uma relação de afeto, igualmente calcada no vício de consentimento originário, impondo-lhe os deveres daí advindos, sem que, voluntária e conscientemente, o queira - acessível em http://www.ibdfam.org.br/jurisprudencia/3147/Negatória\%20 de\%20paternidade.\%20Filiação\%20socioafetiva.

42 Direito Civil..., cit., p. 248. 
extraídos da convivência e não a vontade ou consentimento, ou, como foi o caso, o ressentimento ou reação contra a infidelidade do outro cônjuge" 43 .

Por razões semelhantes, e por outras ligadas ao direito probatório, rejeitou-se a ideia de que a recusa de submissão a exames científicos fazia presumir a paternidade do réu, sempre que essa presunção contrariasse uma paternidade sócio-afetiva já constituída ${ }^{44}$.

Por outro lado, a perfilhação é irrevogável, salvo se tiver havido vício de consentimento ou se se demonstrar a total ausência de relação sócio-afetiva entre pai e filho ${ }^{45}$. Segundo o Superior Tribunal de Justiça “(...) mesmo na ausência de ascendência genética, o registro realizado de forma consciente e espontânea consolida a filiação socioafetiva, que deve ter reconhecimento e amparo jurídico" 46 . E em 2007, o STJ brasileiro ${ }^{47}$ já dizia: "O reconhecimento de paternidade é válido se reflete a existência duradoura do vínculo sócio-afetivo entre pais e filhos. A ausência de vínculo biológico é fato que por si só não revela a falsidade da declaração de vontade consubstanciada no ato do reconhecimento. A relação sócio-afetiva é fato que não pode ser, e não é, desconhecido pelo Direito. (...) O STJ vem dando prioridade ao critério biológico para o reconhecimento da filiação naquelas circunstâncias em que há dissenso familiar, onde a relação sócio-afetiva desapareceu ou nunca existiu. Não se pode impor os deveres de cuidado, de carinho e de sustento a alguém

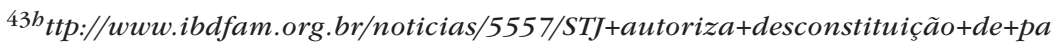
ternidade+mesmo+após+cinco+anos+de+convivência

44 Paulo LôBo, Socioafetividade..., cit, p. 1754-5.

45 "A retificação do registro civil de nascimento, com supressão do nome do genitor, somente se admite quando existir nos autos prova cabal de ocorrência de vício de consentimento no ato registral ou, em situação excepcional, em face da demonstração de total ausência de relação socioafetiva entre pai e filho". TJ-RS Apelação Cível AC 70039828009 RS (TJ-RS), 31/05/2011.

46 Caio Mário da Silva PereIRA, ob. cit., p. 400.

47 RECURSO ESPECIAL No 878.941 - DF (2006/0086284-0)
} 
que, não sendo o pai biológico, também não deseja ser pai sócio-afetivo. A contrario sensu, se o afeto persiste de forma que pais e filhos constroem uma relação de mútuo auxílio, respeito e amparo, é acertado desconsiderar o vínculo meramente sanguíneo, para reconhecer a existência de filiação jurídica".

Em suma, se alguns sistemas jurídicos europeus davam valor à estabilidade das relações constituídas, no interesse do filho, dificultando a impugnação da filiação, o sistema brasileiro ampliou muito o valor da verdade sócio-afetiva baseando a constituição dos vínculos na prova de que se criou um laço afetivo duradouro, ou assentando a impugnação da filiação na prova de que não chegou a formar-se, ou desapareceu, uma convivência familiar. A investigação da paternidade biológica é uma questão da tutela da personalidade; o estabelecimento da filiação, para ser um assunto de direito da família, exige a comprovação de uma convivência familiar de natureza sócio-afetiva ${ }^{48}$.

\section{Co-responsabilidades}

Para além da crise do "modelo biologista" para a determinação da paternidade, as relações de família verticais desenvolvem-se através de uma crescente partilha de responsabilidades. A intenção clara é a de reforçar os laços de convivência em que a criança ou o jovem vive, e garantir a sua manutenção no caso de ocorrer alguma vicissitude.

48 Resta saber que consequências é que esta noção de filiação sócio-afetiva vai ter no direito sucessório, designadamente na restrição da liberdade de testar por força do instituto da sucessão legitimária. Cfr. T. Lemos PEREIRA - Deserdação por abandono afetivo, acessível em http://www.familiaesucessoes.com.br/?p=1612 e E. ROCA I TRIAS - Libertad y Familia, Valência, Tirant lo Blanche, 2014, p. 228-235. 
a) Partilha de responsabilidades parentais com o cônjuge de um progenitor ou com a pessoa em união de facto com esse progenitor

$\mathrm{Na}$ maioria dos países, a investidura em responsabilidades parentais sobre uma criança ou jovem só pode atingir-se através da adoção ${ }^{49}$ do filho do cônjuge ou da pessoa com quem se vive em união de facto, nas condições em que a adoção é permitida.

Para além disto, em alguns países europeus, a pessoa casada com um progenitor que exerça responsabilidades parentais, ou que viva em união de facto com ele, pode partilhar essas responsabilidades, isto é, exercer os mesmos direitos e cumprir os mesmos deveres que os progenitores.

Os regimes variam bastante ${ }^{50}$. Pode admitir-se essa partilha por acordo com o progenitor com quem convive, se apenas este exerce responsabilidades parentais, ou com os dois progenitores (UK), ou por decisão judicial (Finlândia); pode admitir-se essa partilha só quando a criança ou o jovem não tem laços jurídicos com um segundo progenitor (Holanda); a partilha opera-se por força da lei (Holanda); a aquisição de responsabilidades por um convivente pode fazer diminuir as responsabilidades de um dos progenitores (Áustria).

Em Portugal, na sequência do insucesso parlamentar da co-adoção, foram apresentados dois projetos de lei51 que pretendiam alargar o regime de atribuição das responsabilidades parentais em caso de impedimentos ou de morte de um titular. Ambos tinham em mente, suponho, o exemplo divulgado amplamente pelos proponentes da co-adoção: "Está em causa evitar, por exemplo, situações conhecidas e dolorosas de descrever pela sua crueldade: basta imaginar uma criança, educada por dois homens casados, até aos 10 anos de

49 Para uma informação atualizada até 2007, veja-se K. BOELE-WOELKI ed. Principles of European Family Law Regarding Parental Responsibilities, Antewerpen/ Oxford, Intersentia/CEFL, 2007, p. 69.

50 K. BOELE-WOELKI ed. - Principles of European Family Law ..., cit., p. 69-71.

51 Pj1607/XII, do PS, e pj1786/XII, do PSD e do CDS. 
idade, morrendo nessa data o pai biológico num acidente. Aquela criança, que não distingue a nenhum nível qualquer dos pais, não tem, no entanto, o mais ténue vínculo jurídico com o, para si, pai sobrevivente. Pode mesmo vir a ser arrancada dos seus braços pela família do pai falecido, mesmo que não tenha tido qualquer contacto com ela ao longo da sua vida" 52 .

Os dois projetos de lei pretendiam garantir que a criança ou o jovem que convivesse com um dos progenitores e com o cônjuge deste, ou o unido de facto com este, mantivesse os laços com o adulto com quem convive. No caso de impedimento ou de morte do progenitor, o exercício das responsabilidades parentais pertenceria ao progenitor sobrevivo, como resulta já hoje do código civil; mas se este não pudesse assumir este estatuto, as responsabilidades seriam deferidas à pessoa que convivesse com o progenitor sobrevivo. A diferença mais nítida entre os dois diplomas ${ }^{53}$ estava no seguinte: no projeto do PSD/CDS, previa-se que, sendo as responsabilidades parentais exercidas apenas por um progenitor, o tribunal podia atribuí-las também ao cônjuge dele, ou ao unido de facto com ele, a requerimento de ambos, com audiência da criança ou do jovem salvo se isto se mostrasse inconveniente, sendo a extensão das responsabilidades definidas em cada caso. Ou seja, previa-se um regime de partilha de responsabilidades em condições normais, e não apenas nos casos de impedimento ou de morte do progenitor responsável. A Lei n. ${ }^{\circ}$ 137/2015, de 7 de setembro, consagrou uma versão parecida com esta última, embora limitada aos casos em que a filiação se encontre estabelecida apenas quanto a um dos progenitores.

52 Preâmbulo do Projeto de Lei n. ${ }^{\circ}$ 278/XII, subscrito por vários deputados e deputadas do PS, em 2012.

53 Também não é de desprezar a circunstância de o projeto de lei do PSD/CDS afastar uma expressão imprópria que foi introduzida na Assembleia, em 2008, na parte final do art. 1903..$^{\circ}$ "... e com validação legal”. 


\section{b) Um estatuto minimo para os padrastos e madrastas}

Não sendo possível partilhar inteiramente as responsabilidades parentais, procura-se, em todo o espaço europeu, um estatuto jurídico mínimo para os cônjuges dos progenitores com filhos à sua guarda ou, mais amplamente, para todos os companheiros desses progenitores. $\mathrm{O}$ homem que vive com a mãe pode autorizar a prática de um ato médico banal sobre a criança? O cônjuge da mãe pode assinar uma autorização para a deslocação de uma criança em visita de estudo?

Estas pessoas, embora estejam presentes no quotidiano das crianças, e portanto desempenhem papéis fundamentais no cuidado destas, beneficiam de uma escassa consideração jurídica nos sistemas jurídicos. Em alguns países, a própria linguagem, e o imaginário infantil clássico, desvalorizam a figura os cônjuges ou companheiros - são os padrastos e as madrastas ${ }^{54}$. Para além dos países que preveem uma verdadeira partilha total de todas responsabilidades parentais, em alguns lugares, prevê-se um estatuto mínimo55: é o caso da Suíça ${ }^{56}$ e da República Checa ${ }^{57}$, onde a pessoa que vive com um progenitor que tenha responsabilidades parentais pode exercer responsabilidades nos "assuntos da vida corrente"; também é o caso da Alemanha ${ }^{58}$, onde o regime é semelhante mas se exige expressamente que o progenitor convivente exerça as responsabilidades parentais em exclusivo; e parece que se pratica este regime, mesmo sem lei que o preveja, em muitos outros países ${ }^{59}$.

54 "A vida é madrasta...", "uns são filhos e outros enteados...".

55 Para uma informação atualizada até 2007, veja-se K. BOELE-WOELKI ed. Principles of European Family Law ..., cit., p. 71 e 116-8.

56 Art. 299. ${ }^{\circ}$ do Código Suíço.

57 Art. $33 .^{\circ}$ do Código da Família.

58 Par. 1687 b, do BGB; § 9 da Lebenspartnerschaftsgesetz.

59 CEFL - Principles of European Family Law regarding Parental Responsibilities, Antwerpen/Oxford, Intersentia, 2007, p. 116-7. 
No Brasil, a Lei n. ${ }^{\circ} 11.924^{60}$, mandou aditar à Lei dos Registros Públicos a possibilidade de o enteado requerer o aditamento dos apelidos de família do padrasto ou madrasta, com a concordância destes e sem prejuízo dos apelidos da família original.

Em Portugal, a Lei $n .^{\circ}$ 61/2008 introduziu uma regra que pode aplicar-se neste contexto - o art. 1906..$^{\circ}$, n. $^{\circ} 4$ : "O progenitor a quem cabe o exercício das responsabilidades parentais relativas aos actos da vida corrente pode exercê-las por si ou delegar o seu exercício". Este texto, embora sem o dizer expressamente, quis autorizar o progenitor com quem o filho vive, ou com quem ele se encontra temporariamente, a delegar os seus poderes de exercício, livremente, num novo cônjuge ou companheiro. Os seus poderes de exercício podem ser delegados sem o titular ter de pedir autorização ao outro progenitor, e sem se "presumir" o consentimento deste - o titular é livre de os ceder. Daí que não haja lugar à manifestação de objeções por parte do outro titular das responsabilidades parentais.

\section{c) Multiparentalidade}

Nos Estados Unidos - na Califórnia - o Supremo Tribunal admitiu que uma criança podia ter "dupla maternidade" em três casos decididos em 2005. Embora com diferenças, os casos mostravam sempre o nascimento de uma criança dentro de um casal de mulheres homossexuais que mais tarde se separou; e a mulher que não era a mãe biológica, insatisfeita com os remédios tradicionais da atribuição de direitos de visita e até com a atribuição da guarda, reclamou o estatuto de mãe. O Tribunal afirmou, em suma, que o facto de partilhar o projeto de gerar os filhos e de tratá-los como próprios no quadro da relação de união de facto implica a atribuição da maternidade legal, o que protege o interesse superior do me-

60 De 17 de Abril de 2009. 
nor ${ }^{61}$. Sobretudo num dos casos, o tribunal aplicou analogicamente a section 7611, d) do Código da Família que presume pai o homem que acolhe o filho em sua casa e o trata como filho. Salvo erro, porém, esta norma apenas prevê uma compreensível e tradicional presunção da paternidade biológica, e não um fundamento novo da paternidade (ou da maternidade) assente nas relações de paternidade de facto e que exclui a progenitura natural; afirmação que sustento com a leitura de todo o regime que baseia a paternidade na verdade biológica ou na adoção (cfr. p. ex., section 7610). No fim de 2013, o estado da Califórnia promulgou uma lei no mesmo sentido, depois de dois anos de discussão e de um veto do Governador. O argumento decisivo, mais uma vez, foi a satisfação do interesse da criança e os danos para a sua estabilidade que uma solução diversa implicaria ${ }^{62}$.

Também o tribunal de recurso de Ontário, em 2/1/2007, proferiu uma sentença conhecida como o "Three parents case"63. Nesta hipótese, uma mulher que vivia num casal homossexual, e teve um filho, beneficiando do auxílio de um amigo. Ao pretender-se estabelecer a filiação da criança, perguntou-se quem é mãe e quem é pai? A mãe é a mulher que teve o parto, naturalmente; mas também a mulher que vive com ela, ou que é casada com ela, porque também desempenha o mesmo papel de mãe. E o pai é o homem que forneceu o esperma - o pai biológico - que quer ter uma função ativa no cuidado da criança, aliás com o acordo das duas mulheres. Parecia não bastar atribuir a qualquer dos três interessados as responsabilidades parentais sem thes reconhecer um verdadeiro

${ }^{61}$ FARNÓs Amorós, S. y GARRIGA Gorina, M. (2005): “¿Madres? Pueden ser más de una", InDret 4, pp. 306-313.

62 Senate Bill No. 274 CHAPTER 564

(1) "This bill would authorize a court to find that more than 2 persons with a claim to parentage, as specified, are parents if the court finds that recognizing only 2 parents would be detrimental to the child (...)". O regime consta hoje do Código da Família, section 7612 c).

63 Acessível em http://www.samesexmarriage.ca/docs/abc030107.pdf 
estatuto de "pais"; não foi considerado satisfatório reconhecer duas figuras parentais e atribuir à terceira pessoa um direito de visita amplo, porque esta solução não refletia a intensidade das relações afetivas entre todos. Em suma, nenhuma das três pessoas admitia ser excluída da parentalidade, nenhuma admitia assumir um estatuto inferior ao das outras, e todas estavam de acordo sobre isto. E o tribunal de recurso canadiano admitiu que o melhor interesse da criança era o de ter três figuras parentais - duas mães e um pai.

$O$ tribunal entendeu que as leis vigentes destinavam-se apenas a garantir a igualdade de estatutos dos filhos nascidos dentro ou fora do casamento; e tinha em mente as uniões tradicionais entre um homem e uma mulher. Os outros tipos de relacionamento familiar não foram considerados porque simplesmente foram o produto da medicina da reprodução que não se tinha desenvolvido na época. $\mathrm{O}$ tribunal reconheceu que as condições se modificaram e que a legislação mostrava lacunas que era necessário preencher, no interesse das crianças, como nos casos em que a criança tinha duas mães ou dois pais. Estas duas mães ou estes dois pais "são tão pais como os adotivos ou os naturais", disse o tribunal ${ }^{64}$. E acrescentou: "É contrário ao interesse da criança que ela seja privada do reconhecimento de uma das suas mães"65.

Desde então, têm surgido outros casos semelhantes no Canadá.

Designadamente, a lei em vigor na Colúmbia Britânica permite que, para além da mãe biológica, outra mulher casada com ela, ou vivendo em união de facto com ela, seja registada como mãe ${ }^{66}$.

${ }^{64}$ Cfr. o acórdão, n. ${ }^{\circ}[35]$.

65 Idem, n. ${ }^{\circ}$ [37].

66 Family Law Act [sbc 2011] chapter 25, par. 27:

(3) Subject to section 28 [parentage if assisted reproduction after death], in addition to the child's birth mother, a person who was married to, or in a marriage-like relationship with, the child's birth mother when the child was conceived is also the child's parent unless there is proof that, before the child was conceived, the 
No Brasil ${ }^{67}$, em 2012, o Tribunal de Justiça de S. Paulo ${ }^{68}$ aceitou a inscrição de duas mães no registo civil, relativamente a uma criança nascida por inseminação com dador e que foi gerada por uma das mulheres. O Tribunal invocou, sobretudo, o princípio constitucional da dignidade da pessoa humana, o princípio da igualdade e o objetivo constitucional de "promover o bem de todos sem preconceito de (...) sexo (...)". Terá sido a primeira vez que a inscrição foi autorizada sem necessidade de prévio processo de adoção.

Em Minas Gerais, em 2014, invocados os mesmos princípios, o Tribunal de Justiça pronunciou-se do mesmo modo69, apesar do parecer contrário do ministério público que, alegando que a criança tinha acabado de nascer, fazia notar que não se podia fazer prova da posse de estado de filho e da verdade sócio-afetiva. O caso mostrou, pois, que a mera vontade concordante das duas mulheres foi suficiente para justificar a inscrição da dupla maternidade.

No Rio de Janeiro, um acórdão de $2013^{70}$, numa situação semelhante, também sem a preocupação de demonstrar uma situação de facto consolidada pela verdade sócio-afetiva, aceitou a inscrição das duas mães no registo, acrescentando aos fundamentos constitucionais a ideia de que a dupla maternidade consagra o "superior interesse da criança". E exprime ainda, com clareza, que as duas mulheres "buscam converter um vínculo precário (...) para um vínculo institucionalizado (...)".

person (a) did not consent to be the child's parent, or (b) withdrew the consent to be the child's parent.

${ }^{67}$ A descrição seguinte não pretende ser exaustiva.

68 Acessível em http://ibdfam.org.br/imagens_up/Regi.pdf

69 Acessível em http://ibdfam.org.br/jurisprudencia/2934/\%20Dupla\%20maternidade.\%20Possibilidade

${ }^{70}$ Acessível em http://ibdfam.org.br/jurisprudencia/2312/Declaração\%20de\%20 dupla\%20maternidade. $\% 20$ Parcerias $\% 20$ do $\% 20$ mesmo $\% 20$ sexo $\% 20$ que $\% 20$ objetivam $\% 20$ declaração\%20para\%20serem\%20genitoras\%20de\%20filho.\%20Reprodução\%20assistida 
No Rio Grande do Sul, foi apreciado um caso em que o registo de uma criança continha o nome da mãe biológica e o nome do homem com quem ela vivera desde a gestação - o pai sócio-afetivo. Mais tarde, o pai biológico logrou fazer a prova pericial da sua paternidade e requereu que o seu nome fosse acrescentado ao registo. Em face da anuência de todos - e até de um acordo que estabelecia o regime de visitas e de prestação de alimentos - o Tribunal de Justiça decidiu que deviam constar do registo os dois pais e a mãe. Invocou, sobretudo, a consistência da paternidade sócio-afetiva que impedia o afastamento do nome do pai que constava do registo, e também o melhor interesse da criança. Mais tarde, num acórdão de 201571, o mesmo Tribunal de Justiça determinou que uma criança devia ser registada com duas mães e um pai; a mãe biológica era casada com outra mulher, e o homem era o progenitor. O Tribunal entendeu que a lei era omissa e sentiu-se legitimado para usar os instrumentos típicos para a integração das lacunas. Invocou os argumentos já habituais e acentuou o princípio da afetividade, notando que o critério biológico não é o critério exclusivo na formação do vínculo familiar; acrescentou que, deste modo, a criança terá uma "rede de afetos" ainda mais diversificada a amparar o seu desenvolvimento.

No Acre, o Tribunal de Justiça aceitou, em 2014, a inscrição do nome do pai biológico ao lado do pai sócio-afetivo, num caso semelhante ao que foi apreciado pelo Tribunal de Justiça do Rio Grande do Sul.

Em Espanha, as leis da procriação medicamente assistida já ofereciam hipóteses em que a constituição de vínculos de filiação se afastavam da verdade biológica. A hipótese mais conhecida referia-se ao caso já tornado clássico da paternidade do marido da mãe em inseminação com esperma de dador. Para além deste caso - e na

\footnotetext{
${ }^{71}$ Acessivel em http://ibdfam.org.br/assets/img/upload/files/TJRS\%2013_02_2015. pdf
} 
sequência da aprovação de matrimónios entre pessoas do mesmo sexo - a lei da PMA foi emendada por forma a reconhecer a maternidade da pessoa casada com a mãe biológica ${ }^{72}$. Para este efeito, foram previstos requisitos especiais, aplicáveis à situação nova: a) nascimento do filho mediante técnicas de reprodução assistida, b) existência de matrimónio entre a mãe gestante e a declarante, c) que a declaração se faça depois da celebração do casamento, sem que as cônjuges se encontrem separadas legalmente ou de facto, e antes do nascimento, perante o Encarregado do Registo Civil do domicílio conjugal.

Porém, duas sentenças recentes do Tribunal Supremo alargaram o regime e aceitaram a pretensão da ex-companheira da mãe biológica que pedia que fosse reconhecida também a sua maternidade relativamente à criança nascida por procriação assistida com intervenção de um dador anónimo, apesar de não ter havido casamento nem declaração no registo de nascimento. A autora alegava a sua relação de facto com a criança - a posse de estado de filho - e o interesse desta em manter relações de proximidade com ela. É certo que, em 2011, perante factos e pretensão semelhantes, o Tribunal Supremo limitou-se a reconhecer à autora a condição de "pessoa próxima", conferindo-lhe direitos de visita generosos, no interesse da criança; porém, nos dois casos seguintes, apesar de não ter havido alterações legislativas, o Tribunal reconheceu a maternidade da ex-companheira. Na verdade, o Tribunal Supremo mobilizou o art. $131 .^{\circ}$ do código civil, introduzido em 1981, com um sentido discutível: em vez de o encarar como uma norma sobre legitimidade para a reclamação da filiação biológica, entendeu-a como um modo distinto

${ }^{72}$ Ley $3 / 2007$, de 15 de marzo, aditando um n. 3 ao art. $7 .^{\circ}$ da Ley 14/2006, de 26 de mayo:

3. Cuando la mujer estuviere casada, y no separada legalmente o de hecho, con otra mujer, esta última podrá manifestar ante el Encargado del Registro Civil del domicilio conyugal, que consiente en que cuando nazca el hijo de su cónyuge, se determine a su favor la filiación respecto del nacido. 
e autónomo de estabelecimento da filiação ${ }^{73}$. Ou seja - embora se situe no âmbito da procriação medicamente assistida - ultrapassou as regras especiais que estão previstas para este âmbito e, usando uma norma clássica do código civil com um sentido diferente do habitual, fez assentar a filiação na verificação da posse de estado e numa aplicação analógica discutível das normas especiais da lei da Procriação assistida.

Não pode prever-se com segurança a evolução deste tema, dadas as críticas manifestadas e o impressivo voto de vencido que acompanha o acórdão. Mas se prevalecer a ideia de que o art. 131. do código civil pode ser interpretado como uma via autónoma de estabelecimento da filiação com base na posse de estado, o regime espanhol só ficará distante do regime brasileiro porque ainda não se consegue ler na Constituição espanhola uma norma que faça prevalecer a filiação afetiva sobre a filiação biológica.

Nos países escandinavos ${ }^{74}$, com a exceção da Dinamarca e da Finlândia 75 , a criança pode ter dois "parents" registados, que podem ser duas mães. Na Noruega (2009) a cônjuge da mãe biológica é considerada mãe ex lege, a maternidade da companheira em união de facto resulta de um ato específico de consentimento ou de uma ordem do tribunal. Na Islândia (2010), a maternidade da segunda mulher casada também se estabelece ex lege, por força do consentimento prestado para a inseminação, e através de uma ordem do tribunal no caso de união de facto. Na Suécia (2005), a maternidade da segunda mulher não se estabelece por força da lei, ainda que

73 Para uma crítica pormenorizada da sentença de 15 de janeiro de 2014 veja-se R. BARBER Cárcamo - Doble maternidad legal, filiación y relaciones parentales, "Derecho Privado y Constitución", n. ${ }^{\circ}$ 28, 2014, p. 93-136.

${ }^{74}$ Cfr. JANTERA-JAREBORG - Parenthooh for same-sex couples - Scandinavian developments, in "K. BOELE-WOELKI; A. FUCHS, Legal recognition of same-sex relatioships in Europe, 2 nd. Cambridge, Antwerp, Portland, Intersentia, 2012", p. 108-111.

75 Onde a maternidade da segunda mulher tem de resultar de uma adoção. 
as duas sejam casadas, mas sempre por consentimento dela ou por ordem do tribunal ${ }^{76}$.

Sublinho, neste ponto, que a multiparentalidade nasceu na sequência da legitimação das uniões do mesmo sexo, fossem casamentos ou uniões de facto; nasceu para dar resposta às pretensões da mulher que não era a mãe biológica mas queria ter um estatuto jurídico igual relativamente ao filho nascido por inseminação com dador. No Brasil, porém, a multiparentalidade ultrapassou as questões da procriação assistida e das uniões do mesmo sexo para acolher a paternidade biológica e a paternidade sócio-afetiva, no alegado interesse do filho.

\section{d) Apadrinhamento civil}

$\mathrm{O}$ apadrinhamento civil foi introduzido no direito português pela Lei n. ${ }^{\circ}$ 103/2009, de 11 de setembro, regulamentada pelo Decreto-Lei n. ${ }^{\circ}$ 121/2010, de 27 de outubro. De acordo com a definição legal, "o apadrinhamento civil é uma relação jurídica, tendencialmente de carácter permanente, entre uma criança ou jovem e uma pessoa singular ou uma família que exerça os poderes e deveres próprios dos pais e que com ele estabeleçam vínculos afectivos que permitam o seu bem-estar e desenvolvimento, constituída por homologação

\footnotetext{
${ }^{76}$ Nesta al. c) não refiro a hipótese concretizada recentemente no Reino Unido de uma criança ser fruto de um embrião originado pela fecundação, pelo sémen do pai, de um óvulo da mãe, cujo citoplasma foi trocado com o citoplasma de um óvulo alheio. O objetivo desta intervenção foi o de evitar a declaração de doenças graves resultantes de deficiências mitocondriais da mãe. As mitocôndrias apenas fornecem a energia necessária para o desenvolvimento vital; o património genético da criança será o dos seus dois pais. Por esta razão, não considero este caso como uma exceção à parentalidade tradicional - cfr. http://www.sciencealert.com/this-girl-was-born-with-three-biological-parents.

Também não considero a hipótese - por enquanto laboratorial - de dois homens fornecerem células estaminais que são diferenciadas respetivamente em espermatozoide e em óvulo, de tal modo que a fusão dos dois resultará num embrião típico. Recorrendo a uma maternidade sub-rogada para efeitos de gestação, aqueles homens serão os dois progenitores da criança - cfr. http://www.sciencealert.com/two-dad-babies-could-soon-be-a-reality.
} 
ou decisão judicial e sujeita a registo civil". Ou seja, os padrinhos exercem plenamente as responsabilidades parentais, embora não assumam a qualidade de pais. Por sua vez, os progenitores continuam a ser juridicamente pais, embora não exerçam mais do que um pequeno conjunto de direitos que são fixados no compromisso de apadrinhamento, de entre um quadro que a lei prevê e de acordo com as circunstâncias do caso; e esse pequeno conjunto pode ser diminuído sempre que o interesse da criança ou do jovem o recomende ${ }^{77}$.

Em circunstâncias normais, pode falar-se em repartição das responsabilidades porque os pais mantêm um direito de visita e um direito de acompanhar o desenvolvimento do filho; porque a Lei estabelece um dever de colaboração entre os pais e os padrinhos - "Os pais e padrinhos devem cooperar na criação das condições adequadas ao bem-estar e desenvolvimento do afilhado"78; e, em último caso, os pais também estão legitimados para tomar a iniciativa de requer a revogação do apadrinhamento civil, se tiverem subscrito o compromisso de apadrinhamento ${ }^{79}$, em condições excepcionais que mostrem que a manutenção do vínculo não favorece o interesse da criança ou do jovem ${ }^{80}$.

77 Art. $8 .^{\circ}$ : “1 - Os pais, (...) beneficiam dos direitos expressamente consignados no compromisso de apadrinhamento civil, designadamente: $a$ ) Conhecer a identidade dos padrinhos; $b$ ) Dispor de uma forma de contactar os padrinhos; $c$ ) Saber o local de residência do filho; $d$ ) Dispor de uma forma de contactar o filho; $e$ ) Ser informados sobre o desenvolvimento integral do filho, a sua progressão escolar ou profissional, a ocorrência de factos particularmente relevantes ou de problemas graves, nomeadamente de saúde; $f$ ) Receber com regularidade fotografias ou outro registo de imagem do filho; $g$ ) Visitar o filho, nas condições fixadas no compromisso ou na decisão judicial, designadamente por ocasião de datas especialmente significativas. 2 - O tribunal pode estabelecer limitações aos direitos enunciados nas alíneas $d$ ) e $g$ ) do número anterior quando os pais, no exercício destes direitos, ponham em risco a segurança ou a saúde física ou psíquica da criança ou do jovem ou comprometam o êxito da relação de apadrinhamento civil.”

78 Art. 9. ${ }^{\circ}, \mathrm{n} .^{\circ} 2$.

79 Arts. $25 .^{\circ}$, n. $^{\circ} 1,17 .^{\circ}$, b) e $14 .^{\circ}$, n. $\left.^{\circ} 1, \mathrm{c}\right)$

80 Art. $25 .^{\circ}$. 
Sublinho, neste contexto, o teor do art. 9..$^{\circ}$ que impõe ainda aos pais e padrinhos um dever mútuo de respeito e de preservação da intimidade da vida privada e familiar, do bom nome e da reputação.

\section{Conclusões}

I. A "verdade sociológica" serve para constituir a relação de filiação.

A "verdade sociológica" podia servir para proteger as situações de convivência consolidadas e favoráveis ao interesse do filho, contra a ação da impugnação. Em Espanha e na França, o direito da filiação deu sempre guarida a esta ideia ${ }^{81}$. Em 1976, no primeiro artigo que escrevi ${ }^{82}$, mostrei abertura para a verdade sociológica quando afirmei que esta podia ser "mais rica de conteúdo e mais útil à vocação ordenadora do Direito do que a nua realidade biológica". E ainda "Pai é o que dá a vida (...) mas o pai é também aquele que paga os "biberons", citando um dramaturgo francês ${ }^{83}$. Em 1983, desenvolvi esta inclinação a propósito do regime da impugnação da paternidade do marido ${ }^{84}$ e do perfilhante ${ }^{85}$. Este último regime era tão submisso à descoberta da verdade biológica que só se podia compreender pelo desprezo a que eram votadas as relações familiares constituídas fora do casamento; de facto, a verdade biológica não era o critério jurídico relevante, na época em que as normas nasceram, no código de Seabra. O que impressiona, neste regime, é a extrema facilidade com que se pode invocar um interesse moral ou patrimonial para

81 Cfr. supra, nota 4.

82 Sobre a verdade e a ficção no direito da família, "Boletim da Faculdade de Direito da Universidade de Coimbra», vol. LI, 1976, p....

83 Marcel PAGNOL, em Marius, 1929.

84 Critério jurídico da paternidade, 1983, p. 390.

85 Critério ..., p. 433 e segs. 
impugnar, a qualquer tempo, com o resultado possível de destruir vidas inteiras de convivência tranquila. Em 2006, voltei a manifestar dúvidas sobre a conveniência de um "biologismo" estrito que possa valer contra estados de parentalidade constituídos, pacíficos e duradouros ${ }^{86}$, para, afinal, satisfazer interesses que podem ser apenas patrimoniais. Continuo hoje convencido de que a descoberta da verdade biológica não compensa os danos que causa, em certas hipóteses, quando se impugnam estados de convivência familiar dignos de proteção, sobretudo no interesse do filho.

Mas a evolução dos sistemas jurídicos mencionados foi mais longe. Para além de usar a posse de estado de filho para proteger as situações familiares estabilizadas, admite a demonstração da verdade sócio-afetiva para estabelecer a filiação, num misto de relevância da vontade de assumir um estatuto parental e da força legitimadora das situações de facto. É aqui que reside a novidade ${ }^{87}$.

II. O desempenho da função não satisfaz; é preciso ser-se titular do estatuto de pai ou de mãe.

$\mathrm{Na}$ verdade, a proteção das crianças - designadamente das que são criadas por duas mulheres - podia ser conseguida através do estabelecimento da maternidade da mãe biológica e da atribuição plena das responsabilidades parentais à cônjuge ou companheira em união de facto. Esta atribuição responderia às angústias de que se fala quanto ao eventual desaparecimento da mãe e do risco de a criança ser entregue a alguém da família biológica que, afinal, nem

86 Curso de Direito da Família, vol. II, tomo I, Estabelecimento da Filiação $e$ Adoção, Coimbra, Coimbra Editora, 2006, p. 140, 183-4, 186 e 190.

87 É certo que, antes da reforma de 1977, em Portugal e nos outros países latinos, o estabelecimento da paternidade (e até maternidade) não tinha de se submeter à verdade biológica, e resultava do casamento da mãe através da presunção pater is est... e da perfilhação entendida como verdadeira declaração de vontade. Mas, depois da reforma de 1977, o "império do biologismo", confortado com os progressos científicos, parecia ter superado aqueles outros critérios jurídicos para sempre. 
conhece, com preterição da pessoa verdadeiramente indicada para a substituir. Porém, em vários exemplos mencionados, verifica-se que o reconhecimento oficial da função de cuidador e a proteção consequente do seu desempenho não satisfazem os cuidadores, que não aceitam menos do que o título e o estatuto de pai ou mãe. Assim aconteceu, claramente, nos vários casos que deram origem ao registo de multiparentalidade.

III. Usa-se o "estabelecimento da filiação" para satisfazer o "interesse do filho".

Tradicionalmente - nos sistemas "biologistas" - a filiação resulta do facto biológico da responsabilidade dos progenitores na concepção; o pai e a mãe jurídicos são o pai e a mãe biológicos. Neste momento do estabelecimento da filiação não se aprecia o interesse do filho em iniciar, ou não iniciar, uma relação jurídica com qualquer deles; os factos biológicos são determinantes e o Direito sujeita-se a isso. Logo a seguir, admitem-se todas as demonstrações de que o pai ou a mãe não têm capacidades parentais, de tal modo que podem ser imediatamente destituídos das responsabilidades parentais, ou ver o seu exercício limitado pelas conveniências do filho.

Porém, em vários casos de multiparentalidade referidos, invoca-se claramente a defesa do interesse superior da criança para estabelecer uma segunda maternidade ou uma segunda paternidade. Ou seja, enquanto, tradicionalmente, os conceitos de "estabelecimento da filiação" e de "interesse do filho" operavam em áreas de intervenção distintas, hoje tende a usar-se a constituição do estado de filho como instrumento de satisfação do interesse da criança ${ }^{88}$ - omitir o registo de uma segunda mãe, ou de um segundo pai, seria contrário

88 Cfr. R. BARBER Cárcamo - Doble maternidad legal..., cit., p. 34-5. Por sua vez, o código da Califórnia é expresso neste sentido - "(...) if the court finds that recognizing only 2 parents would be detrimental to the child (...)"- cfr. supra, a nota 52. 
ao interesse da criança, enquanto reconhecer duas mães ou dois pais visa satisfazer o interesse da criança.

IV. Um direito da família com mais relevância da vontade

Dizia-se, tradicionalmente, que o direito da família era o sector do direito civil onde se encontravam mais normas imperativas - quer por força de um pensamento institucionalista que via a família como uma realidade anterior ao direito positivo, quer pela necessidade de proteger interesses públicos que não se encontravam com a mesma nitidez no âmbito do direito civil patrimonial. Isto não deixou de ser assim; na esfera da constituição do estado de casado, ou da sua dissolução, e até nos modos de constituir as relações de filiação ou de as impugnar, etc., continua a ser verdade que as "partes" não podem escolher livremente os modos de configurar e exercer as suas relações jurídicas.

Mas, aparentemente, o sistema imperativo tradicional, e o princípio do respeito pela verdade biológica, já não conseguem disciplinar totalmente a sociedade contemporânea e as aspirações dos indivíduos. Na verdade, alguns dos exemplos referidos mostram que a jurisprudência não respeita o princípio da taxatividade dos meios de estabelecimento da filiação; passou para além das normas e legitimou o alargamento do critério da vontade associado à assunção da responsabilidade pelo cuidado da criança; afinal, pode ser pai ou mãe a pessoa que deseja, ama e cria uma criança ${ }^{89}$, sem consideração de qualquer vínculo biológico. De certo modo, parece regressar triunfante a noção de "perfilhação de complacência", que assentava na vontade de assumir o estatuto de pai, porventura para disfarçar o velho estigma da ilegitimidade; hoje, o desejo tem de ser

89 "Desta forma, deve o registro de nascimento da menor retratar a sua realidade social. De forma a demonstrar que foi desejada, amada e criada por duas mães" - TJMG, em Dezembro de 2014 (cfr. nota 58). 
acompanhado de uma relação de cuidado ou, pelo menos, de uma promessa de cuidado ${ }^{90}$.

Por outro lado, apesar de termos chegado até aqui com base no método da reprodução sexuada - nem menos do que dois, nem mais do que dois - as últimas décadas conduziram-nos aos avanços da genética que não permitem conservar as leis a que nos habituámos. Num curto período de tempo, algumas certezas e imposições legais assentes na imitação da natureza desmoronaram-se: a multiparentalidade é o caso. E deixando assim os legisladores a braços com as maiores perplexidades, só restará o caminho para a retirada e para deixar a livre escolha aos indivíduos e à sua regulação do caso concreto91, ampliando a expressiva frase "a lei é a ausência de lei" 92.

Talvez este caminho seja inevitável; e, seguramente, as sociedades hão de saber lidar com esses novos fenómenos, como sempre aconteceu ${ }^{93}$. Mas pode ser temerário abandonar tão radicalmente, e em tão pouco tempo, as referências biológicas mais simples e consistentes que se conhecem - as noções biológicas de pai e de mãe.

V. O direito português contém os ingredientes típicos para a evolução.

Não pode ignorar-se que o direito português, como a generalidade dos países próximos, contém os ingredientes típicos de onde partiu a evolução que outros países encetaram. Para sublinhar os

90 É sem dúvida curioso que as relações de parentalidade de facto concorram - e por vezes superem - os vínculos biológicos, numa época em que estes podem comprovar-se facilmente.

91 E. ROCA I TRIAS - Libertad y Familia ..., p. 239.

92 Embora concebida para caracterizar a vida do casal por U. BECK y E. BECKGERNSHEIM - El normal..., p. 346.

93 VESÁlio tinha de se esconder para dissecar partes do corpo humano e estabelecer as bases da anatomia; as transfusões de sangue também começaram por ser consideradas criminosas; e o médico alemão FORSSMANN, que fez chegar um cateter ao seu próprio coração, deixou de poder exercer cardiologia, durante algum tempo, na primeira metade do século vinte. 
mais importantes, pode dizer-se que, em Portugal, foi sempre relativamente tolerada a "perfilhação de complacência", apesar das amplas (e até insólitas) possibilidades de impugnação que a lei sempre previu; é generalizado o instituto da adoção, que tem sido alvo de uma promoção considerável por parte do legislador; e também se tornou comum estabelecer a paternidade do marido da mulher que recorreu a inseminação com dador. Isto é, as hipóteses de constituição da paternidade com fundamento na vontade e na assunção das responsabilidades pelo cuidado são conbecidas há muito no direito português. Depois disto, os progressos da medicina da reprodução, aliados ao reconhecimento das uniões de facto e casamentos entre pessoas do mesmo sexo que o nosso Direito consagra, ampliam definitivamente as oportunidades para se vir a pretender a construção de uma parentalidade cada vez mais desligada do ancestral vínculo biológico, e a construção de uma multiparentalidade.

VI. Tal como está, o sistema português ${ }^{94}$ ainda não reconhece a "verdade sócio-afetiva" (a posse de estado de filho) como fundamento normal e suficiente para estabelecer a paternidade ou a maternidade; a tradicional posse de estado só serve como presunção do vínculo biológico, em ações de investigação de filiação (arts. $1816 .^{\circ}$ e $1871 .^{\circ}$

\footnotetext{
${ }^{94}$ Partindo do princípio do respeito pela verdade biológica que inspirou a reforma de 1977, o nosso sistema jurídico pretende fazer coincidir a filiação jurídica com a filiação biológica. Esta regra geral carece de precisão quanto à maternidade, e admite exceções. Quanto à maternidade, o facto biológico que releva é o parto, e não a contribuição do material genético através da fecundação do óvulo. Esta opção não existia antes da prática da reprodução assistida; mas passou a existir quando uma mulher pode gerar um óvulo fecundado pertencente a outra mulher. Quanto às exceções, podem ser referidas, para além da que resulta da adoção: a) o estabelecimento da paternidade do marido da mãe que recorre a inseminação com dador (Lei $32 / 2006$, de 26 de julho, art. $20 .^{\circ}$ ); b) a persistência de um vínculo jurídico que eventualmente não assentar na progenitura, mas que não puder ser impugnado por virtude do decurso de um prazo de caducidade (arts. $1817 .^{\circ}$ e $1873 .^{\circ}$ CCiv); c) o regime da perfilhação de filhos maiores, ou de filhos pré-defuntos de quem vivam descendentes maiores ou emancipados, cuja eficácia depende do consentimento daqueles ou destes (art. 1857. ${ }^{\circ}$ CCiv).
} 
CCiv). O sistema português também não admite a dupla maternidade, que se tem apresentado, como vimos atrás, como a pretensão de duas mulheres levarem o seu nome ao registo civil, sendo uma a mãe biológica e a outra a sua cônjuge ou companheira em união de facto. E também não acolhe a multiparentalidade, que se tem apresentado no estrangeiro como o desejo de acrescentar um pai às duas mães; ou quando um progenitor se quer acrescentar ao pai (sócio-afetivo) que consta já do registo, e à mãe.

A verdade é que, no que respeita à constituição do estado de filho, o direito português ainda segue a máxima antiga de que o interesse do filho "é pertencer ao pai cujo é" Também tem parecido dominante a ideia de que o interesse do filho reclama a inscrição no registo civil de $u m$ pai e $u m a$ mãe ${ }^{96}$. Assim, a pretensão de constituir um vínculo baseado na vontade e numa relação afetiva, ou na promessa dela, ou a pretensão de constituir mais do que dois vínculos de maternidade ou de paternidade, ou ainda a pretensão de levar três nomes "parentais" ao registo civil, não têm tido suporte no direito português.

A satisfação do "interesse superior da criança" - que tem sido alegada para justificar a evolução referida em vários sistemas jurídicos - ainda só pode ser obtida, em Portugal, através da atribuição das responsabilidades parentais - através da confiança a terceira pessoa (art. 1907. ${ }^{\circ}$ CCiv), da instauração da tutela (art. 1921. ${ }^{\circ}$ CCiv), do apadrinhamento civil (DL 103/2009, de 11 de setembro), ou da confiança em vista de adoção, ressalvada sempre a verificação dos requisitos legais próprios de cada instituto; e poderá vir a receber

95 Assento do STJ de 22 de junho de 1938, disponível em http://www.dgsi.pt/ jstj.nsf/954f0ce6ad9dd8b980256b5f003fa814/23abc30cdd810779802568fc003a6b9c ?OpenDocument

96 Não apenas como uma faculdade mas também como um dever, como se depreende da consagração, logo em 1966, do instituto da averiguação oficiosa. 
um novo caminho, brevemente, na sequência das iniciativas parlamentares que visam construir uma alternativa à co-adoção97.

Provavelmente, este modo de proteção do interesse do filho ${ }^{98}$ quer conciliar as efetivas necessidades de promoção dos interesses dos menores com a preservação dos conceitos básicos e tradicionais da maternidade única e da paternidade única, supondo, talvez, que o abandono do entendimento habitual destes conceitos gera um potencial risco social de discriminação para a criança99.

97 Supra, n. ${ }^{\circ} 5$, a).

98 Sem prejuízo, é claro, dos instrumentos específicos do sistema de proteção das crianças e dos jovens que se encontram em situação de perigo.

99 O texto foi escrito antes da aprovação, pela Assembleia da República, da adoção por casais do mesmo sexo. 